\title{
Proving Triptycene Homoconjugation with the Same Chromophore but Different Connectivity to the Core
}

\author{
Sven M. Elbert ${ }^{\mathrm{a}}$ \\ Tobias Kirschbaum ${ }^{a}$ \\ Frank Rominger ${ }^{a}$ \\ Michael Mastalerz ${ }^{* a}$ \\ a Organisch-Chemisches Institut, Ruprecht-Karls-Universität Heidelberg, Im \\ Neuenheimer Feld 270, 69120 Heidelberg, Germany \\ michael.mastalerz@oci.uni-heidelberg.de \\ Dedicated to Prof. Dr. Peter Bäuerle on the Occasion of his 65th Birthday.
}

Received: 15.01.2021

Accepted after revision: 4.02.2021

DOI: 10.1055/s-0041-1726304; Art ID: om-21-0005sc

License terms: CC $(\$$

(c) 2021. The Author(s). This is an open access article published by Thieme under the terms of the Creative Commons Attribution-NonDerivative-NonCommercial License, permitting copying and reproduction so long as the original work is given appropriate credit. Contents may not be used for commercial purposes, or adapted, remixed, transformed or built upon. (https://creativecommons.org/licenses/by-nc-nd/4.0/)

Abstract Homoconjugation is a phenomenon discussed for various $\pi$ systems where classical conjugation is broken by e.g. methylene units but still a stabilization by electronic communication exists. In this respect, triptycene with its rigid $C_{3}$ symmetric geometry is an ideal scaffold to study this phenomenon. Although several studies based on triptycene strengthen the hypothesis of homoconjugation, in all described cases the electronic communication through space relies on different $\pi$-blades. Here, two triptycenes are presented having the exact same $\pi$-extended chromophore, but differently annulated to the bicyclic core. Both compounds were investigated by spectroscopic as well as computational means and compared with the corresponding model compound, elucidating the influence of the attachment site to the triptycene core on potential homoconjugation.

Key words triptycenes, homoconjugation, Pictet-Spengler reaction, three-dimensional $\pi$-extended molecules

\section{Introduction}

Homoconjugation is an effect influencing the electronic properties of molecules by "through space" orbital interactions. ${ }^{1,2}$ In this respect, especially triptycene was investigated in depth $\mathrm{h}^{3,4}$ and already early reports describe spectroscopic differences between triptycene and triphenylmethane, which can only be explained by homoconjugation effects. ${ }^{5}$ It was in 1983 when Martin et al. used photoelectron spectroscopy in combination with theoretical calculations to finally prove the existence of homoconjugation. ${ }^{6}$ These findings have been picked up

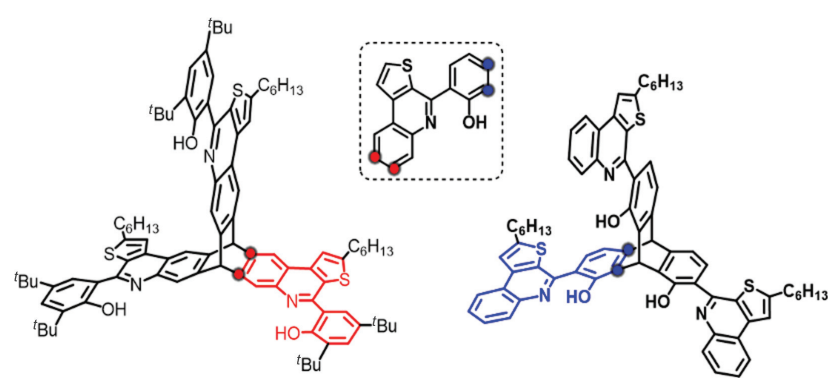

more recently by studies on dialkoxytriptycenes and their oxidations to the corresponding quinones by Rathore and coworkers in solution and in silico. ${ }^{7}$ Additionally, empirical results such as the possibility to monosubstitute triptycene in electrophilic aromatic substitution reactions, such as nitrations, rather than obtaining statistical mixtures of mono-, di-, and trisubstituted triptycenes underline the assumption of an electronic communication between the triptycene paddles, influencing the reactivity of each other. ${ }^{8-10}$ Recently, a series of 15 triptycene derivatives with different donor and acceptor moieties has been reported, clearly showing how homoconjugation influences the donating or accepting nature of identical acceptor and donor units depending on their number. ${ }^{11}$

With the exception of the photoelectron spectroscopic evidence of the homoconjugation for unsubstituted triptycene, ${ }^{6}$ all other contributions rely on either different $\pi$ systems which are connected via the bicyclic core $e^{1,4,11,12}$ or comparing different twofold substitution patterns (orthoor para-dimethoxy triptycenes) and their oxidation behavior. ${ }^{7}$ Rathore et al. calculated possible homoconjugation of a variety of structurally related triptycenes with enlarged $\pi$-blades or better chromophores on the bicyclic backbone with the outcome that subtle structural changes can have a significant impact on homoconjugation effects. ${ }^{7}$ However, they came to the conclusion that the nodal arrangement of the HOMO orbital coefficients found at the closest atoms of the core can be used to define the amount of homoconjugation. ${ }^{7}$

To the best of our knowledge, homoconjugation has not been investigated for constitutional isomers having the same chromophore (Figure 1) just connected in a different way to the bicyclic core, which is presented herein. The chromophore $^{13}$ used in this study is attached either at the thienoquinoline unit (Figure 1, red dots) or at the phenol ring (Figure 1, blue dots) to the 2-, 3-, 5-, 6-, 7-, and 8-positions of the bicyclo[2.2.2] octane core. 


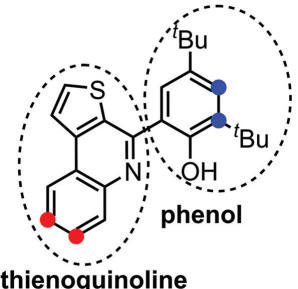

Figure 1 Chromophore 1 with its thienoquinoline as well as phenol substructure highlighted and the sites of ring fusion to the bicyclo [2.2.2]octane scaffold in red (at the thienoquinoline part) and blue (at the phenolic part).

\section{Results and Discussion}

The synthesis of the triptycene-based thienoquinoline $\mathbf{8}$ started from trisamido triptycene $\mathbf{2}^{9,10,14}$ which was threefold brominated (NBS, DMF) to give triptycene $\mathbf{3}$ in $88 \%$ yield (Scheme 1$){ }^{15}$ After acidic amide cleavage $(\mathrm{HCl}$, $\mathrm{EtOH}$ ), triamino, tribromo triptycene $\mathbf{4}^{16}$ was isolated in $97 \%$ yield. Subsequent Suzuki-Miyaura cross-coupling with the hexyl-substituted thiophene boronic acid ester $5^{17}$ under $\mathrm{Fu}$ conditions $\left(\mathrm{Pd}_{2} \mathrm{dba}_{3}, \mathrm{HP}^{t} \mathrm{Bu}_{3} \mathrm{BF}_{4}\right)^{18}$ gave $86 \%$ of triptycene 6 after purification (Scheme 1 ).

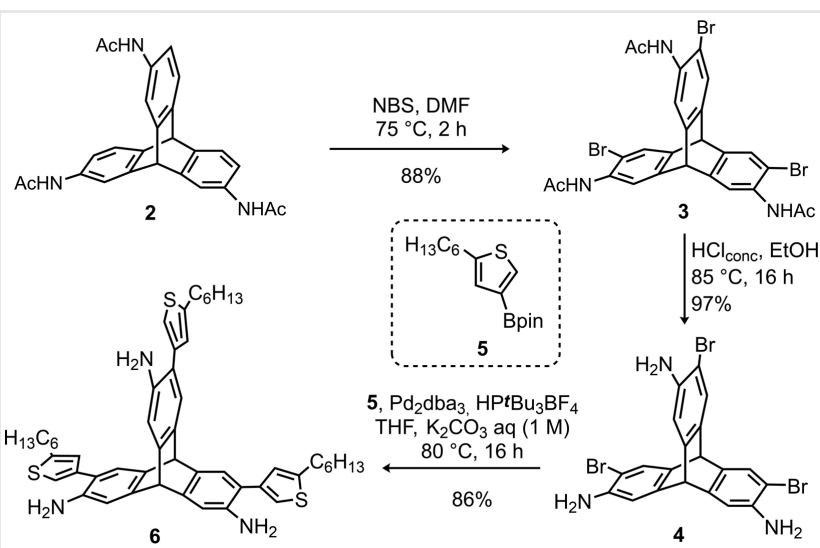

Scheme 1 Synthesis of the triptycene-based threefold 2-aryl amine 6.

Triamino, triaryl triptycene 6 was reacted with di-tertbutylsalicylaldehyde 7 under Pictet-Spengler conditions [PhMe, TFA (10 mol\%), $\left.\mathrm{O}_{2}, 100{ }^{\circ} \mathrm{C}, 3 \mathrm{~h}\right]^{13,19}$ to finally give 8 in $55 \%$ yield after recrystallization from a chloroform/ethanol mixture (Scheme 2). The synthesis of the structural isomer ${ }^{20}$ 11 was achieved also by a threefold Pictet-Spengler reaction. Here, triptycene tris-salicylaldehyde $\mathbf{9}^{21}$ was reacted with ortho-hexylthieno aniline $\mathbf{1 0}$ (for details on the synthesis, see the Supporting Information) under the aforementioned

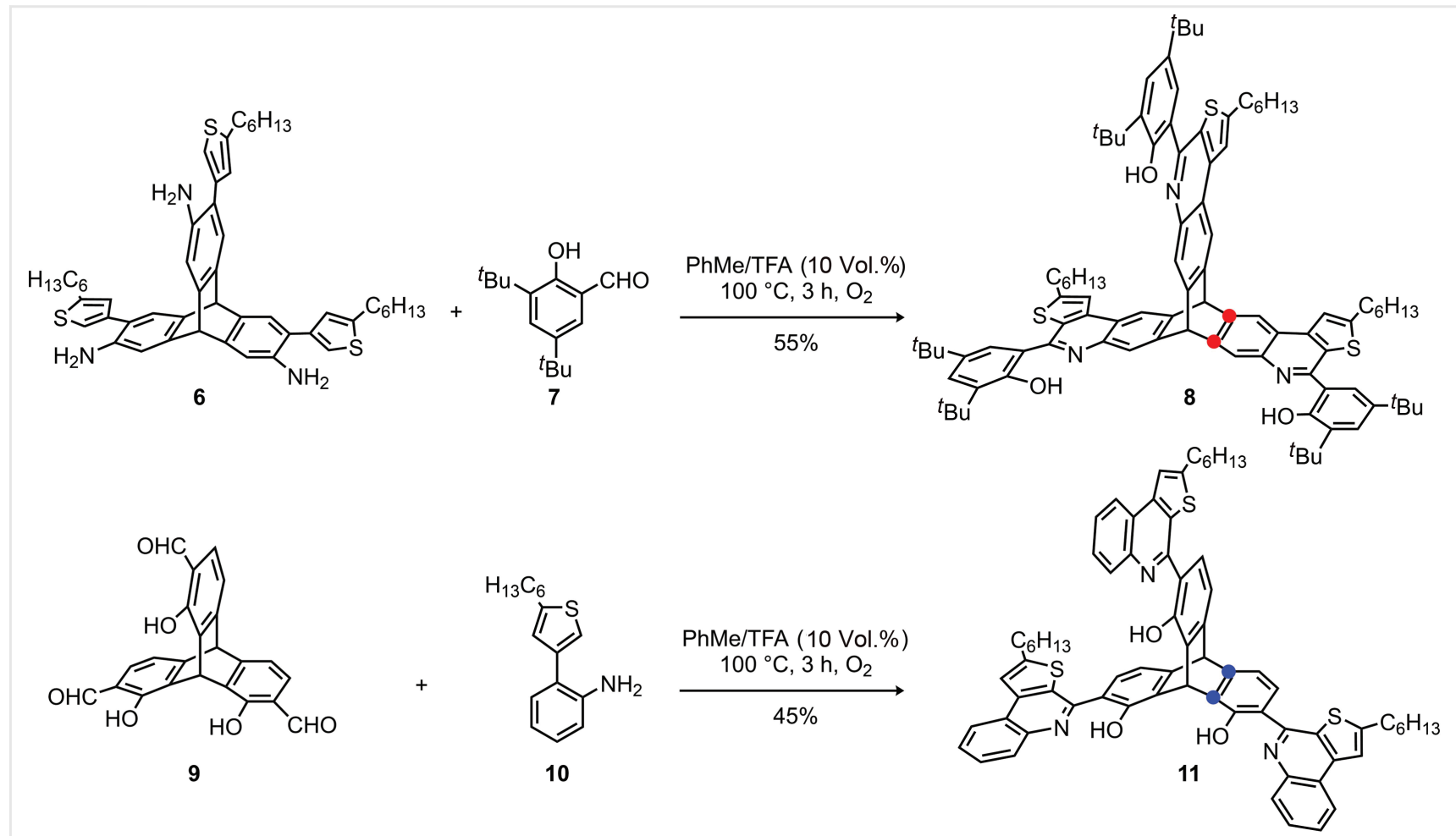

Scheme 2 Synthesis of the triptycene-based threefold chromophores $\mathbf{8}$ and $\mathbf{1 1}$. The red and blue dots highlight the attachment site at the thienoquinolinic (red, 8) and the phenolic (blue, 11) substructures. 


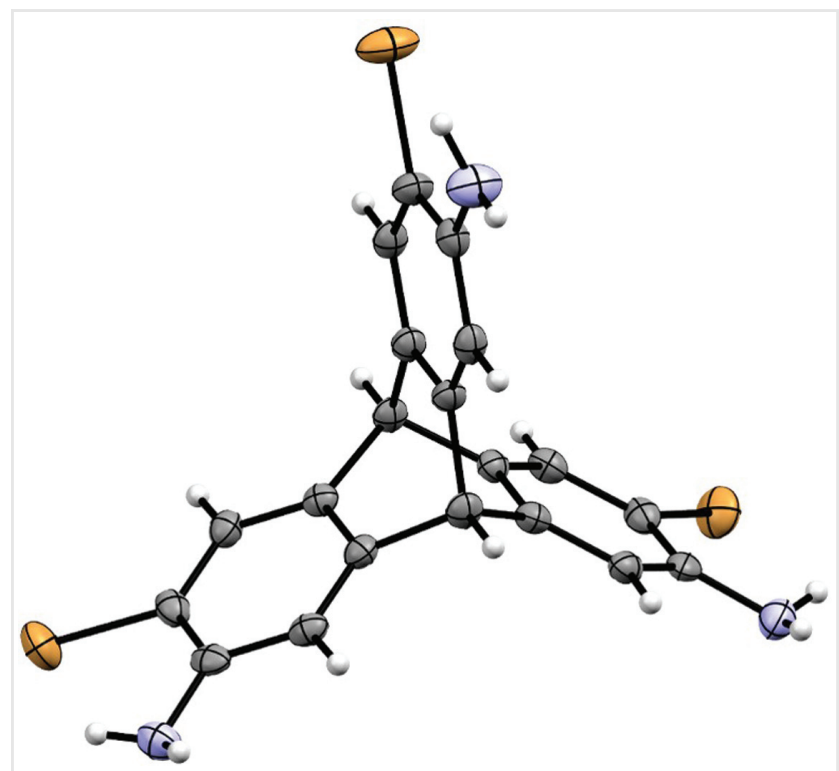

Figure 2 Single crystal X-ray structure of triptycene $\mathbf{4}$ as ORTEP plot with thermal ellipsoids at the 50\% probability level. Carbon: grey; hydrogen: white; nitrogen: blue; bromine: light brown.

conditions. After precipitation from dichloromethane and washing with $n$-pentane, $\mathbf{1 1}$ was isolated in $45 \%$ yield. All obtained triptycene derivatives have been fully characterized (see the Supporting Information) and the structure of triamino, tribromo triptycene $\mathbf{4}$ was unambiguously proven by single-crystal X-ray diffraction (Figure 2 ).

Triptycenes $\mathbf{8}$ and $\mathbf{1 1}$ were examined by UV/vis spectroscopy in chloroform and the obtained results were compared with model compound 1, representing one isolated chromophore of the other two (Figure 3). For 1 a highest wavelength absorption maximum at $\lambda_{\mathrm{abs}}$ $=364 \mathrm{~nm}$ and additional maxima at $\lambda_{\mathrm{abs}}=311 \mathrm{~nm}$ and $\lambda_{\mathrm{abs}}=272 \mathrm{~nm}$ were observed. Triptycene 11 shows a comparable highest wavelength absorption at $\lambda_{\mathrm{abs}}=363$ $\mathrm{nm}$ and an additional maximum at $\lambda_{\mathrm{abs}}=308 \mathrm{~nm}$, as well as a shoulder at $\lambda_{\text {abs }}=265 \mathrm{~nm}$. In contrast to 1 and 11, triptycene 8 has a bathochromically shifted $(\Delta \lambda=13-14 \mathrm{~nm})$ longest wavelength absorption at $\lambda_{\mathrm{abs}}$ $=377 \mathrm{~nm}$. Furthermore, a maximum of high intensity at $\lambda_{\mathrm{abs}}=272 \mathrm{~nm}$ makes a clear spectroscopic difference for 8 and 11. Since both compounds have the same chromophore, this difference is assigned to homoconjugation effects rather than inductive effects of the two tert-butyl substituents found in $\mathbf{8} .^{22}$

To get a deeper understanding of the electronic properties of the three compounds, for the aromatic backbones of $\mathbf{1}, \mathbf{8}$ and 11, models without alkyl substituents (denoted as $\mathbf{1}^{\prime}, \mathbf{8}^{\prime}$, and $\mathbf{1 1}^{\prime}$ ) have been investigated by dispersion-corrected (GD3BJ) density

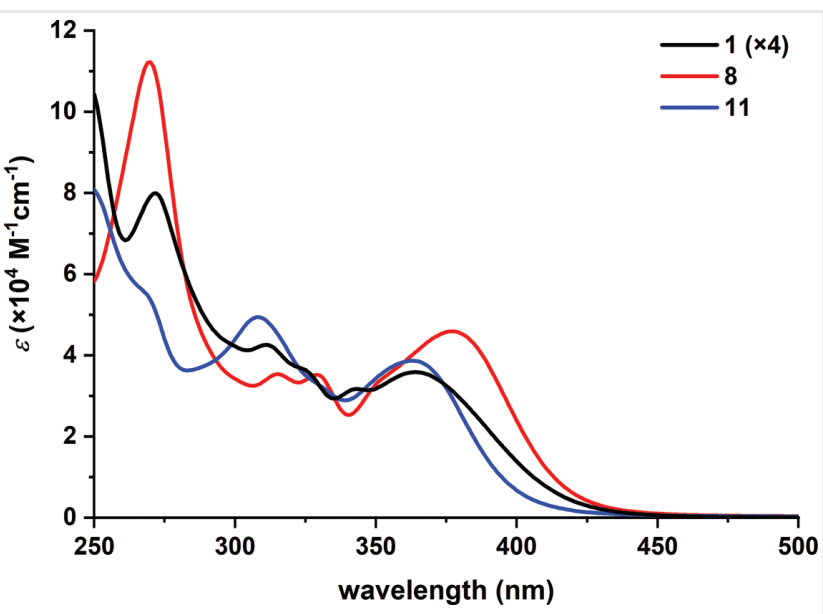

Figure 3 UV/vis-spectra of $\mathbf{1}$ (black) and triptycenes $\mathbf{8}$ (red) and $\mathbf{1 1}$ (blue) in chloroform at room temperature. The spectrum of $\mathbf{1}$ is shown in fourfold intensity.

functional theory (DFT) calculation [B3LYP-6-311(d,p); Figure 4$].^{23}$ For model compound 1', the HOMO energy level is found at $E_{\mathrm{HOMO}}=-5.90 \mathrm{eV}$ with the largest atom orbital coefficients at the phenolic substructure. Nevertheless, the HOMO is also distributed over the thienoquinoline part of the molecule (Figure 4, left). The corresponding LUMO can be found delocalized over the whole molecule, here the main proportion of orbital coefficients is found at the thienoquinoline unit. The energy level is at $E_{\mathrm{LUMO}}=-2.11 \mathrm{eV}$, resulting in a gap of $\Delta E_{\text {Hомо-LUMо, DFT }}=3.79 \mathrm{eV}$.

For triptycene $\mathbf{8}^{\prime}$ bearing three of those chromophores, the HOMO energy is destabilized by $+0.09 \mathrm{eV}\left(E_{\text {номо }}=-5.81 \mathrm{eV}\right)$ in comparison to $\mathbf{1}^{\prime}$. In contrast, the degenerated LUMOs are stabilized by $-0.14 \mathrm{eV}\left(E_{\mathrm{LUMO}}=-2.25 \mathrm{eV}\right)$ and the HOMOLUMO gap is slightly decreased to $\Delta E_{\text {HOMO-LUMO DFT }}=3.56 \mathrm{eV}$. This destabilization in HOMO energy of the triptycene vs. the monomeric chromophore of about $0.1 \mathrm{eV}$ is in agreement with Rathore et al.'s suggestion. ${ }^{7}$ Furthermore, the nodal arrangement of HOMO coefficients is comparable to all compounds, where homoconjugation was suggested to be found (Figure 5). ${ }^{7}$

More interesting than comparing model compound 1' with triptycene $\mathbf{8}^{\prime}$ is the comparison of the two isomeric triptycenes $\mathbf{8}^{\prime}$ and $\mathbf{1 1}^{\prime}$. In contrast to $\mathbf{8}^{\prime}$, the HOMO coefficients of $\mathbf{1 1}^{\prime}$ are located on the phenol units exclusively, whereas those of the LUMO are delocalized over the whole backbones of the chromophore units (Figures 4 and 5). For 11', both HOMO and LUMO are destabilized by $+0.28 \mathrm{eV}\left(E_{\text {Номо }}=-5.53 \mathrm{eV}\right)$ or $+0.40 \mathrm{eV}\left(E_{\mathrm{LUMO}}=-1.85 \mathrm{eV}\right)$ in comparison to $\mathbf{8}^{\prime}$. The resulting $+0.12 \mathrm{eV}$ larger HOMO-LUMO energy gap of $\Delta E_{\text {HOMO-LUMO, }}$ DFT $=3.68 \mathrm{eV}$ is in agreement with the observations made using UV/vis spectroscopy (see above). 


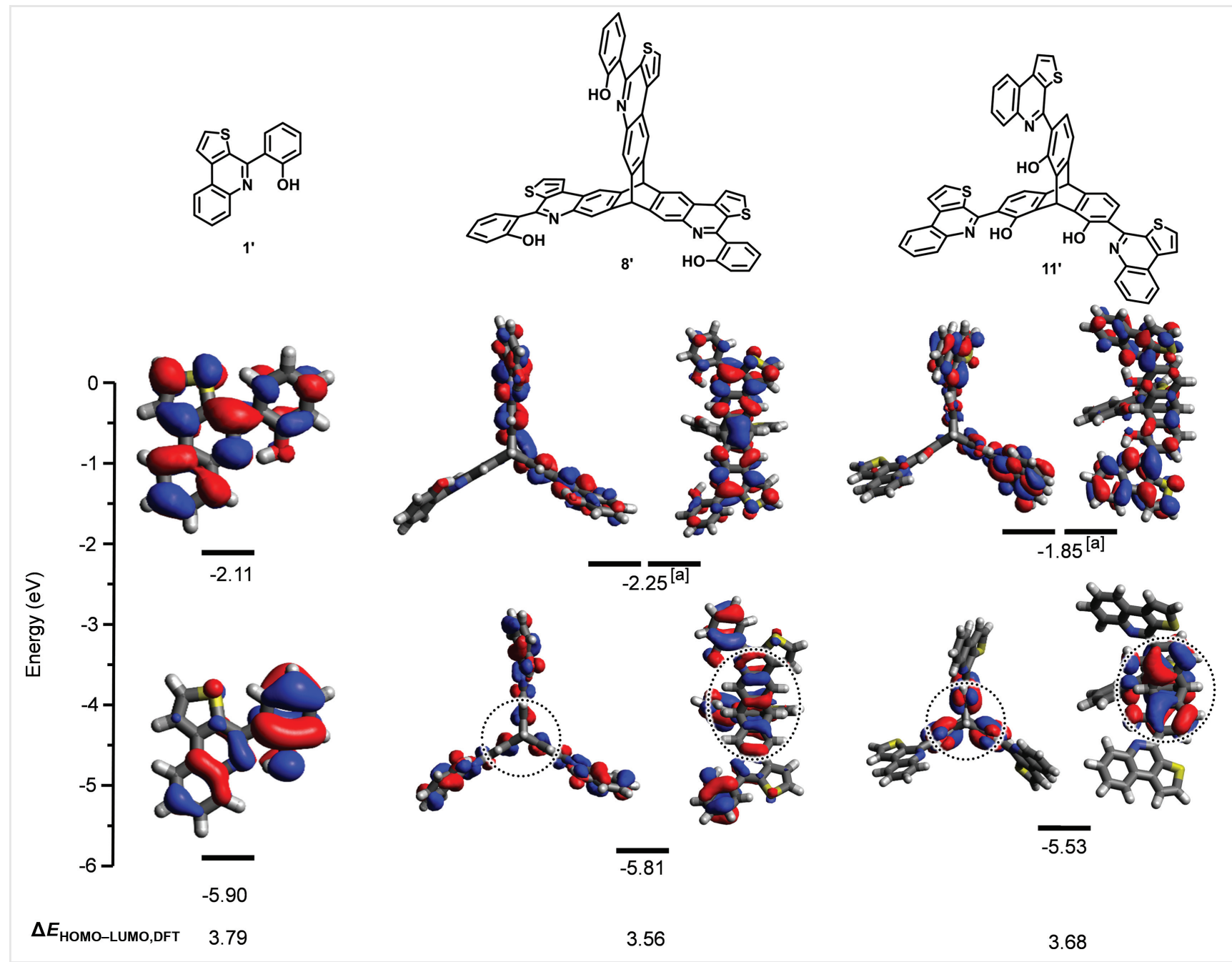

Figure 4 Molecular orbitals and corresponding energy levels of compounds $\mathbf{1}^{\prime}, \mathbf{8}^{\prime}$, and $\mathbf{1 1}$ ' calculated by dispersion-corrected (GD3BJ) DFT methods (B3LYP-6-311(d,p). ${ }^{[a]}$ Note that only one of the degenerated LUMOs is depicted. For the other LUMO depiction, see the Supporting Information. The dotted circles highlight the inner atoms close to the bicyclic core which are depicted in an enlarged form in Figure 5.

According to the assumptions made by Rathore and coworkers, the HOMO destabilization of $\mathbf{1 1}$ to model compound $\mathbf{1}$ is about $370 \mathrm{meV}$, which is one of the largest values found for triptycene-based systems. ${ }^{7}$

Cyclic voltammetry (CV) investigations (Figure 6) of compounds $\mathbf{1}$ and $\mathbf{8}$ show comparable oxidation potentials of $E_{\text {ox,onset }}=0.51 \mathrm{~V}(\mathbf{1})$ and $E_{\text {ox,onset }}=0.47 \mathrm{~V}(\mathbf{8})$ with a slightly lower $(-0.04 \mathrm{~V})$ potential for triptycene $\mathbf{8}$, which is in agreement with the observed small destabilization of the HOMO found by DFT calculations (see above). While $\mathbf{1}$ shows one distinct quasi-reversible oxidation wave, the oxidation processes of triptycene $\mathbf{8}$ are less defined, suggesting an additional oxidation process at higher potentials overlapping with the first oxidation wave. ${ }^{11,24}$ Unfortunately, the solubility of the isomer $\mathbf{1 1}$ was too low to gain more information on homoconjugation effects by $\mathrm{CV}$.

\section{Conclusions}

In summary, two triptycenes with the same $\pi$-extended chromophores yet differently attached to the bicyclic core have been synthesized and compared to a model compound representing one triptycene paddle. The triptycene where the chromophore is attached at the phenolic substructure shows comparable spectroscopic (UV/vis) behavior to the model compound. The attachment at the thienoquinoline unit leads to a bathochromic shift of $\Delta \lambda=13 \mathrm{~nm}$ of the lowest energy absorption which can be attributed to homoconjugation 
a)
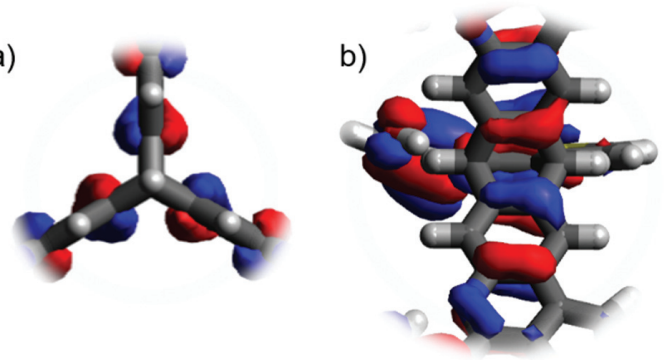

c)

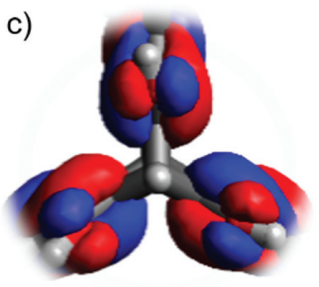

d)

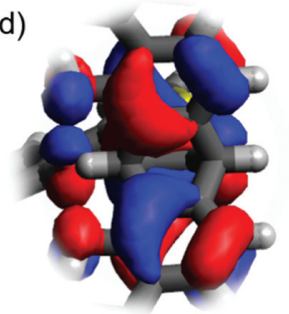

Figure 5 Zoom-in on the HOMOs of compounds $\mathbf{8}^{\prime}$ (a and b) and $\mathbf{1 1}$ (c and d) around the bicyclo[2.2.2] octane core calculated by dispersioncorrected (GD3BJ) DFT methods (B3LYP-6-311(d,p)).

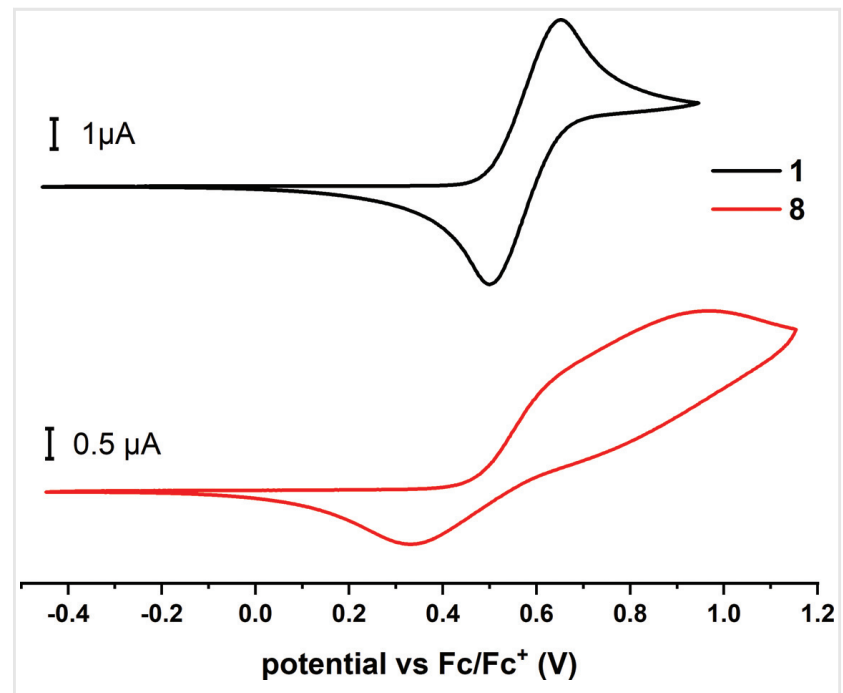

Figure 6 Cyclic voltammograms of model compound $\mathbf{1}$ and triptycene 8 in $\mathrm{CH}_{2} \mathrm{Cl}_{2}$ using $n \mathrm{Bu}_{4} \mathrm{PF}_{6}(0.1 \mathrm{M})$ as the electrolyte with a Pt electrode and $\mathrm{Fc} / \mathrm{Fc}^{+}$as the internal reference (scanning speed: $100 \mathrm{mV} \mathrm{s}^{-1}$ ).

effects. DFT calculations [B3LYP-6-311(d,p) with GD3B] dispersion correction] underline the assumption that the degree of homoconjugation is dependent not only on the nature of the extended aromatic paddle but also on the attachment site due to differences in orbital interaction. These findings clearly demonstrate that electronic and optical properties in three-dimensional $\pi$-extended molecules can be fine-tuned without changing the chromophoric structure by itself, but rather by varying the orientation of chromo-

phores in space. This opportunity expands the toolbox of chromophore design to another dimension. The heredescribed triptycenes $\mathbf{8}$ and $\mathbf{1 1}$ can be used as threefold bidentate $\mathrm{N}, \mathrm{O}$-ligands, e.g. for $\mathrm{BF}_{2}$-complexes, ${ }^{13}$ which are under investigation in our laboratory.

\section{Funding Information}

The authors are grateful to the "Deutsche Forschungsgemeinschaft" for supporting this project within the collaborative research center: SFB1249 "N-heteropolycyclic compounds as functional materials" (TP-A04).

\section{Acknowledgement}

The authors acknowledge support by the state of BadenWürttemberg through bwHPC and the German Research Foundation (DFG) through grant no INST 40/575-1 FUGG (JUSTUS 2 cluster). Lucas Ueberricke is acknowledged for his help during CV measurements and helpful discussions.

\section{Supporting Information}

Supporting Information for this article is available online at: https://doi.org/10.1055/s-0041-1726304.

\section{References And Notes}

(1) Harada, N.; Tamai, Y.; Uda, H. J. Am. Chem. Soc. 1980, 102, 506.

(2) (a) Martin, H.-D.; Mayer, B. Angew. Chem. Int. Ed. Engl. 1983, 22, 283. (b) Murata, I. Pure Appl. Chem. 1983, 55, 323. (c) Ohno, K.; Ishida, T.; Naitoh, Y.; Izumi, Y.J. Am. Chem. Soc. 1985, 107, 8082.

(3) (a) Yamamura, K.; Nakasuji, K.; Murata, I.; Inagaki, S. J. Chem. Soc. Chem. Comm. 1982, 396. (b) Harada, N.; Uda, H.; Nakasuji, K.; Murata, I. J. Chem. Soc., Perkin Trans. 2 1989, 1449.

(4) Kawasumi, K.; Wu, T.; Zhu, T.; Chae, H. S.; Van Voorhis, T.; Baldo, M. A.; Swager, T. M. J. Am. Chem. Soc. 2015, 137, 11908.

(5) Bartlett, P. D.; Lewis, E. S. J. Am. Chem. Soc. 1950, 72, 1005.

(6) Martin, H.-D.; Mayer, B.; Gleiter, R.; Schäfer, W.; Vögtle, F. Chem. Ber. 1983, 116, 2546

(7) Talipov, M. R.; Navale, T. S.; Rathore, R. Angew. Chem. Int. Ed. 2015, 54, 14468

(8) (a) Klanderman, B. H.; Perkins, W. C. J. Org. Chem. 1969, 34, 630. (b) Rees, J. H. J. Chem. Soc., Perkin Trans. 2 1975, 945.

(9) Chong, J. H.; MacLachlan, M. J. Inorg. Chem. 2006, 45, 1442.

(10) Li, P.-F.; Chen, C.-F. J. Org. Chem. 2012, 77, 9250.

(11) Baumgärtner, K.; Hoffmann, M.; Rominger, F.; Elbert, S. M.; Dreuw, A.; Mastalerz, M. J. Org. Chem. 2020, 85, 15256.

(12) (a) Harada, N.; Tamai, Y.; Takuma, Y.; Uda, H. J. Am. Chem. Soc. 1980, 102, 501. (b) Doerner, T.; Gleiter, R.; Neugebauer, F. A. Eur. J. Org. Chem. 1998, 1615.

(13) Elbert, S. M.; Wagner, P.; Kanagasundaram, T.; Rominger, F.; Mastalerz, M. Chem. Eur. J. 2017, 23, 935. 
(14) (a)Zhang, C.; Chen, C.-F.J. Org. Chem. 2006, 71, 6626.(b) Menke, E. H.; Lami, V.; Vaynzof, Y.; Mastalerz, M. Chem. Commun. 2016, 52, 1048.

(15) (a) Skvarchenko, V. R.; Shalaev, V. K.; Klabunovskii, E. I. Russ. Chem. Rev. 1974, 43, 951. (b) Shalaev, V. K.; Getmanova, E. V.; Skvarchenko, V. R. Vestnik Moskov Univ. 1973, 14, 740.

(16) Shalaev, V. K.; Getmanova, E. V.; Skvarchenko, V. R. Zh. Org. Khim. 1976, 12, 191

(17) Yang, X.; Rominger, F.; Mastalerz, M. Org. Lett. 2018, 20, 7270.

(18) Netherton, M. R.; Fu, G. C. Org. Lett. 2001, 3, 4295.

(19) (a) Elbert, S. M.; Reinschmidt, M.; Baumgartner, K.; Rominger, F.; Mastalerz, M. Eur. J. Org. Chem. 2018, 532. (b) Elbert, S. M.; Rominger, F.; Mastalerz, M. Z. Anorg. Allg. Chem. 2018, 644, 606.
(20) The structural isomerism is only referred to the chromophoric units and the central triptycene. The tert-butyl units of $\mathbf{1 1}$ are to be neglected in this respect, yet had to be introduced due to solubility reasons.

(21) Elbert, S. M.; Rominger, F.; Mastalerz, M. Chem. Eur. J. 2014, 20 , 16707.

(22) Coggeshall, N. D.; Glessner, A. S. J. Am. Chem. Soc. 1949, 71, 3150.

(23) Grimme, S.; Ehrlich, S.; Goerigk, L. J. Comput. Chem. 2011, 32, 1456.

(24) Ueberricke, L.; Benke, B. P.; Kirschbaum, T.; Hahn, S.; Rominger, F.; Bunz, U. H. F.; Mastalerz, M. Chem. Eur. J. 2021, 27, 2043. 